\title{
A ETNOGRAFIA COMO MODO DE ENSINAR E APRENDER NA ESCOLA
}

\author{
Graziele Ramos Schweig (UFMG)*
}

https://orcid.org/0000-0003-0590-9742

\section{RESUMO}

Ao explorar maneiras em que a Antropologia pode compor com os modos de fazer na escola, o artigo discute potencialidades do fazer etnográfico como práticas docente e discente no Ensino Médio. Para tanto, parte de uma experiência de pesquisa e ensino com jovens estudantes de uma instituição de educação profissional de Porto Alegre, Rio Grande do Sul. Neste projeto, elementos da investigação etnográfica permearam tanto o fazer docente, na proposição das intervenções pedagógicas, quanto o percurso de aprendizagem dos estudantes. A partir da análise dos diários de campo produzidos, discutese os usos da etnografia enquanto ferramenta de planejamento e intervenção em contextos educativos. Em específico, entende-se a pesquisa etnográfica na escola enquanto prática de "educação da atenção" (INGOLD, 2010) - ou de cultivo da "atenção imanente" (STENGERS, 2017) - operada tanto por parte dos estudantes quanto da professora, favorecendo a composição de um "plano comum" de aprendizagem.

Palavras-chave: Etnografia. Diversidade. Aprendizagem pela pesquisa. Ensinoaprendizagem. Atenção.

\section{ABSTRACT}

\section{ETHNOGRAPHY AS A WAY OF TEACHING AND LEARNING IN SCHOOL}

By exploring how Anthropology can compose with "ways of making" in school, the article discusses the potential of ethnography as teacher and student practices in High School. Therefore, it starts from a research and teaching experience with young students of a vocational education institution in Porto Alegre, Rio Grande do Sul. In this project, elements of ethnographic research permeated both the teaching practice, in the proposition of pedagogical interventions, and the student learning path. From the analysis of field diaries, it discusses the uses of ethnography as a tool for planning and intervention in educative contexts. Specifically, ethnographic research at school is understood as a practice of "education of attention" (INGOLD, 2010) - or of cultivation of "immanent attention" (STENGERS, 2017) - operated both by students and teacher, favoring the composition of a "common plan" of learning.

Keywords: Ethnography. Diversity. Learning through research. Learningteaching. Attention. 


\section{RESUMEN}

\section{LA ETNOGRAFÍA COMO FORMA DE ENSEÑANZA Y APRENDIZAJE EN LA ESCUELA}

Al explorar caminos en que la Antropología compone con las "formas de hacer" en la escuela, el artículo analiza el potencial de la etnografía como práctica en la escuela secundaria. Por lo tanto, parte de una experiencia de investigación y enseñanza con jóvenes estudiantes de una institución de educación vocacional en Porto Alegre, Rio Grande do Sul. En este proyecto, elementos de la investigación etnográfica impregnaron tanto la práctica docente, en intervenciones pedagógicas, como el camino de aprendizaje de los estudiantes. Com los diarios de campo, se discuten los usos de la etnografía como herramienta de planificación e intervención en contextos educativos. En particular, se entiende la investigación etnográfica en la escuela como una práctica de "educación de la atención" (INGOLD, 2010), o de cultivo de la "atención inmanente" (STENGERS, 2017), operada tanto por los estudiantes como por la profesora, favoreciendo la composición de un "plan común" de aprendizaje.

Palabras clave: Etnografía. Diversidad. Aprendizaje por investigación. Enseñanza y aprendizaje. Atención.

\section{Introdução}

Nos últimos anos, a Antropologia tem se feito presente na escola básica dentro do componente curricular "Sociologia", o qual abarca os saberes do conjunto das Ciências Sociais - Antropologia, Sociologia e Ciência Política (BRASIL, 2000, 2006). Além disso, uma série de questões caras à tradição antropológica acabaram por ganhar espaço de modo transversal na escola e nos debates públicos sobre educação no período recente. Em grande medida, isso é fruto de um contexto no qual movimentos sociais e políticas públicas conferiram visibilidade à questão da "diversidade" na educação, incluindo-se aí o papel das ações afirmativas nas Universidades e da Lei no 11.645/2008, que inclui o ensino de História e Cultura Afro -Brasileira e Indígena nos currículos (BRASIL, 2008). Sendo assim, temas como relações étnico-raciais, povos indígenas e tradicionais, identidade cultural, gênero, direitos humanos, entre outros, passaram a permear documentos oficiais, planos pedagógicos, práticas escolares e cursos de formação de professores.

Em uma perspectiva de inseparabilidade entre "conteúdos" a serem aprendidos e "modos" de viver e se relacionar (INGOLD, 2018; JASANOFF, 2004), entende-se que o ensino de questões ligadas a "cultura" e "diversidade" implica a criação de maneiras singulares de entrar em relação. Isto é, além de garantir a presença desses temas nos currículos e normativas oficiais, é necessário desenvolver sensibilidades outras e modos de composição com vivências e problemáticas as mais diversas, que atravessam o espaço da escola e da Universidade. Nesse sentido, das possibilidades de interlocução entre a tradição antropológica e a educação, este artigo busca evidenciar o fazer etnográfico enquanto um modo específico de entrar em relação com o outro e de produzir conhecimento sobre a cultura. Notadamente, discute-se como elementos da etnografia podem figurar enquanto potentes ferramentas no planejamento e intervenção em contextos educativos que busquem promover a diversidade.

Em específico, explora-se os usos da pesquisa etnográfica na escola enquanto prática de "educação da atenção" (INGOLD, 2010, 2016a) - ou arte da "atenção imanente" (STENGERS, 2017). Nesse sentido, o fazer etnográfico é 
aqui considerado, sob uma ótica particular, não apenas como método de descrição ou de coleta de dados para análise, mas como uma forma de se relacionar que possibilita atentar à cultura como "acontecimento" (DELEUZE, 2003), isto é, em sua dimensão emergente. Assim, ao longo do texto, discuto uma experiência realizada com jovens estudantes do Ensino Médio, ${ }^{1}$ na qual se buscou abrir espaço para cultivar a atenção aos processos emergentes vivenciados por eles, compondo processualmente um "plano comum" de aprendizagem. Ou seja, sem delimitações temáticas prévias, lançou-se mão de técnicas e problemáticas contemporâneas que perfazem a etnografia, operacionalizando conceitos centrais como cultura, etnocentrismo, relativismo, poder e violência simbólica, criando-se percursos singulares de investigação onde a análise e a intervenção se misturaram.

\section{A pesquisa etnográfica e sua dimensão educacional}

A etnografia tem sua origem remontada ao trabalho de Bronislaw Malinowski nas Ilhas Trobriand, no início do século XX. Sua pesquisa é considerada uma ruptura com os chamados "antropólogos de gabinete", os quais teorizavam sobre a cultura a partir de relatos de "segunda mão", isto é, por meio de informações obtidas por terceiros, missionários e viajantes. Na obra "Argonautas do Pacífico Ocidental", publicada em 1922, Malinowski (1984) lança as bases do que compreendemos como pesquisa de campo etnográfica: a observação participante. Realizada por meio da convivência prolongada com os sujeitos da pesquisa, a etnografia passou a implicar um deslocamento - geográfico e epistemológico - com relação ao lugar e às categorias de pensamento do pesquisador. Essa maneira de produzir conhecimento sobre

1 Aos sujeitos participantes foi garantido o anonimato. 0 nome da instituição onde foi realizada a pesquisaintervenção é citado no texto dada a fácil identificação em razão de pertencimento institucional prévio da autora. a cultura, permeada por movimentos de estranhamento e familiarização, ao não conceber protocolos de pesquisa replicáveis, constitui-se em um campo dinâmico, apresentando práticas concretas bastante variadas e singulares, como atenta João Pacheco de Oliveira (2009).

Em meio a caminhos possíveis, além de se configurar como "descrição da cultura", dado pelo nome "etno-grafia", o trabalho do antropólogo possui uma importante dimensão educacional, tal como tem enfatizado Tim Ingold (2016a, 2018) em suas produções mais recentes. Ao conviver de modo prolongado com os sujeitos de pesquisa, exercitando uma atitude de suspensão de certezas prévias, os antropólogos passam por um processo de aprendizagem minuciosa, desenvolvendo habilidades de percepção sensível ao outro. A escrita do diário de campo, prática essencial no trabalho de campo, além de sua função de registro, configura-se em uma ferramenta de apoio a esse processo educativo, ao longo do qual as seguranças cotidianas mais banais são postas à prova. Desse modo, para além da objetificação dos sujeitos e situações vivenciadas (ou seja, da produção de "dados", descrições e afirmações sobre o mundo), a observação participante diz respeito a um movimento existencial de "correspondência" com o entorno. Isto é, ela ocorre ao se viver "atencionalmente" com as pessoas com quem se pesquisa e se aprende, colocando-se em uma constante atitude de abertura ao inesperado (INGOLD, 2016a, 2016b).

Nessa abordagem, fazer pesquisa antropológica significa enfrentar um contínuo não-saber, um colocar-se à disposição do movimento do outro, que pode desmanchar nossas hipóteses interpretativas a cada instante. Como reflete Ingold (2016a, p. 408): "Fazê-lo pode ser perturbador, e implicar riscos existenciais consideráveis. É como lançar o barco na direção de um mundo ainda não formado - um mundo no qual as coisas ainda não estão prontas, são sempre incipientes no limiar da emergência contínua." Sob essa ótica, menos do que mapear traços e características de uma determinada cultura, 
o trabalho do antropólogo diz respeito a uma "educação da atenção"2 à emergência das coisas; à cultura em seu devir. Trata-se do cultivo da "arte da imanência” (STENGERS, 2017), um esforço de não-reificação das identidades, mas de acompanhamento de seus processos de contínua transformação.

Esse modo de fazer pesquisa antropológica contribui para a problematização de abordagens essencialistas e culturalistas - as quais se mantém presentes nos debates sobre "cultura" e "diversidade" no âmbito da educação. Como argumentam McDermott e Raley (2011), apesar dessas abordagens não serem dominantes no campo de debates da Antropologia contemporânea, elas parecem persistir em pesquisas antropológica sobre a educação, ao considerarem culturas ou identidades enquanto totalidades homogêneas, reificando processos de vida. Dessa forma, abordar a etnografia na escola como prática de atenção à cultura como acontecimento objetiva fazer um contraponto a essas tendências. Aproximando-se da "proposição cosmopolítica" de Isabelle Stengers (2018), trata-se de "desacelerar" a construção do mundo - das interpretações, dos consensos e coerências - dando lugar à hesitação, possibilitando maior composição com o outro, sem soluções fáceis para o problema da diferença.

Com isso, sob uma atitude de abertura ao inesperado e ao não-saber, colocamo-nos o desafio de fazer a prática etnográfica operar como ferramenta de ensino e aprendizagem na escola - este espaço do saber objetificado em conteúdos a serem ministrados por especialistas. Caminhos para responder a esse desafio foram experimentados em uma proposta de pesquisa e ensino com jovens estudantes do segundo ano do Ensino Médio do Instituto Federal de Educação, Ciência e Tecnologia do

2 Concebendo o processo educativo por meio do engajamento sensível com o entorno, Tim Ingold (2010) define a "educação da atenção" como um processo de contínua afinação do sistema perceptivo do praticante com as propriedades do ambiente. Segundo ele, a aprendizagem da cultura ocorreria muito mais por educação da atenção do que por transmissão ou acúmulo de representações mentais.
Rio Grande do Sul (IFRS) - Campus Restinga, em Porto Alegre, onde atuei como professora de Sociologia/Ciências Sociais. As atividades foram realizadas com três turmas em 2016 e duas turmas em 2017, as quais eram compostas por uma média de 25 alunos. Dentro dos limites (e limitações) de aulas semanais de 50 minutos, a proposta de trabalho para cada ano se deu em torno da realização de pesquisas de orientação etnográfica em grupos, por parte dos alunos. Concomitantemente, acompanhei as atividades por meio da escrita de diários de campo, os quais ajudavam a refletir sobre os caminhos percorridos e a tentar "antecipar" o que emergia (INGOLD, 2012).

O Campus Restinga do IFRS situa-se no bairro que lhe dá nome, em uma região a 30 quilômetros do centro de Porto Alegre, capital do Rio Grande do Sul. A Restinga é um dos bairros mais populosos da periferia da cidade, contando com mais de 60 mil moradores regulares. Sua história é contada a partir de processos de remoção forçada de comunidades majoritariamente negras que habitavam a região central da cidade na década de 1960 (ZAMBONI, 2009). Em 2006, lideranças comunitárias do bairro iniciaram uma campanha pública pela construção da "escola técnica da Restinga", a qual foi contemplada em edital público no contexto da expansão da Rede Federal de Educação Profissional, Científica e Tecnológica, criando-se o Campus Restinga como parte do IFRS. Com início das atividades em 2010, e atendendo em sua maioria estudantes moradores do bairro, atualmente a instituição oferta três formações na modalidade de técnico integrado ao Ensino Médio - Eletrônica, Informática e Lazer -, sendo as atividades aqui narradas realizadas com turmas dos dois primeiros cursos. ${ }^{3}$

3 o Campus Restinga também oferta regularmente dois cursos profissionalizantes na modalidade Educação de Jovens e Adultos (Comércio e Agroecologia), um curso técnico subsequente (Guia de Turismo) e cinco cursos superiores (Licenciatura em Letras, Análise e Desenvolvimento de Sistemas, Eletrônica Industrial, Gestão Desportiva e de Lazer e Processos Gerenciais). 


\section{Começar pelo meio: acessando}

\section{a cultura como acontecimento}

Iniciar uma pesquisa envolve delinear um campo problemático de investigação. Implica a capacidade de tornar questionável algum aspecto do cotidiano que normalmente é tomado como banal, óbvio, natural. ${ }^{4}$ Desde Malinowski, além da familiaridade com conceitos, métodos e técnicas de investigação, vimos que o fazer etnográfico demanda fundamentalmente se deslocar, ou seja, envolve desenvolver uma atenção diferenciada a si e ao entorno. Nas primeiras aulas com as turmas de segundo ano, nos aproximamos de conceitos introdutórios, como cultura, etnocentrismo, relativismo e violência simbólica por meio de filmes, leituras, exercícios teatrais e debates. ${ }^{5}$ Chegava, então, a hora dos estudantes esboçarem um foco problemático em torno do qual caminharia a pesquisa de cunho etnográfico a ser realizada em grupos de até quatro integrantes. Ao serem convidados à proposta de investigação, alguns estudantes demonstraram dúvidas - alegaram ser difícil definir o quê pesquisar diante de tantas possibilidades. Assim seguiu uma das aulas:

Nesse dia foi dada a oportunidade de reunirem-se nos grupos, em sala de aula, para trocarem ideias. A primeira tarefa era escolher um tema de interesse e produzir um pequeno texto justificando sua relação com os conceitos que vínhamos estudando. Enquanto conversavam, eu ia passando para acompanhar as conversas. Nesses deslocamentos, notei que em um grupo de meninos, os alunos estavam tocando e comentando a respeito do cabelo de um dos integrantes. Cheguei mais perto e perguntei como andavam as discussões. Eles comentaram que não tinham ideia sobre o que fazer na pesquisa. Mencionaram alguns temas vagos, mas não pareciam motivados. Con-

4 Cabe lembrar que as Orientações Curriculares Nacionais para o Ensino Médio indicam que as Ciências Sociais na escola têm como papel a "desnaturalização e o estranhamento" dos fenômenos sociais (BRASIL, 2006, p. 107).

5 Não cabendo detalhar neste espaço, ao iniciar o ano letivo, assistimos a vídeos e documentários para sensibilizar os estudantes à escuta de narrativas; trabalhamos com desenho e realizamos jogos teatrais, de modo a preparar a atenção do corpo e do olhar. tinuaram com alguns olhares e comentários sobre o cabelo do colega até que direcionei atenção ao que se atravessava. Diziam que o colega tinha alisado o cabelo, ao que o menino negava, afirmando que seu cabelo era assim mesmo. Logo surgiu a classificação 'cabelo ruim' e 'cabelo bom' em meio ao diálogo. Sugeri a eles que 'cabelo' daria um ótimo tema de pesquisa etnográfica. Eles estranharam, riram. Começamos, então, a pensar o quanto de etnocentrismo havia na classificação que eles tinham acabado de usar. Comentaram sobre como as pessoas são julgadas pela aparência, sobre o racismo implicado nisso. Deram-se conta de que o tipo de cabelo tem influência até no modo como são recebidos nos lugares em que circulam na cidade. Ao final da conversa, indiquei que eles assistissem ao documentário 'Good Hair'6 para a aula seguinte. ${ }^{7}$

Assim, cada grupo saiu dessa aula com alguma tarefa para a semana seguinte. Enquanto alguns já começaram a elaboração de um texto de justificativa, que relacionava seu tema aos conceitos introdutórios que havíamos discutidos, outros ganharam indicações para auxiliar na busca por um foco inicial. Agora eles teriam que transformá-lo em um problema de investigação exequível e que dissesse respeito a um grupo ou fenômeno concreto, observável, de modo que eles pudessem acompanhá-lo por meio de uma pesquisa. As orientações para trabalharmos em diálogo com a etnografia foram construídas especialmente a partir da discussão feita no dia em que assistimos ao documentário Babilônia 2000 (2001), de Eduardo Coutinho. ${ }^{8} \mathrm{Na}$ ocasião, elencamos características de sua narrativa que se aproximavam da pesquisa antropológica. Acordamos, portanto, que deveriam ser elaboradas perguntas de pesquisa que buscassem "saber como a pessoa chegou às ideias que expressa" ou que inten-

6 Dirigido por Jeff Stilson (GOOD..., 2009).

7 Nota do Diário de Campo da pesquisa registrada em abril de 2016.

8 Neste documentário, Eduardo Coutinho e sua equipe acompanham moradores de duas favelas cariocas no dia 31 de dezembro de 1999, em atividades preparativas para o réveillon do ano 2000. Ao assisti-lo, reparamos no modo como o entrevistador/pesquisador não está ausente da cena, em como as perguntas são colocadas para que o entrevistado pense sobre sua vida, bem como na importância da escuta atenta. 
tassem compreender "a perspectiva de quem está envolvido no problema" - entendendo que poderiam ser múltiplos e contraditórios esses pontos de vista. Sendo assim, independentemente do tema aos quais se referiam, as questões de pesquisa tinham por objetivo provocar uma determinada atitude, uma posição de escuta de algum "outro".

Desde a aproximação conceitual inicial até a elaboração das perguntas de investigação, decorreram-se aproximadamente oito semanas de aula. Esse tempo foi importante, pois mesmo antes de nomear questões de investigação, a pesquisa - enquanto "educação da atenção" já estava em curso, tanto para os estudantes quanto para mim. Não houve, portanto, um momento definido a partir do qual a pesquisa passaria a ser executada ou os "dados" coletados. Havia, desde o início, um território que vinha sendo explorado, passo a passo, ao se propiciar um espaço de sensibilização e de atenção às questões vivenciadas pelos estudantes, as quais nem sempre são de fácil ou imediata explicitação. Para pensar sobre esse processo, nos aproximamos da ideia de "começar pelo meio", tal como sugerida por Deleuze e Guattari (1997) e explorada por Eugenio e Fiadeiro (2013). Ao apostar na atenção à imanência do acontecimento, a ideia de começar pelo meio se opõe ao "plano de princípio ou finalidade" (DELEUZE; GUATTARI, 1997, p. 222), que impera nos modos escolares de educação. Isto é, na escola, a delimitação de um conjunto de conteúdos e objetivos prévios normalmente dá o tom da organização curricular, constituindo "modos operativos" que "raramente partem do 'fator de situação' do meio" (EUGENIO; FIADEIR0, 2013, p. 223, grifo dos autores) para produzir conhecimento. Ou seja, as propostas pedagógicas normalmente constituem-se mais em torno da "intenção" do professor (ou do currículo) que seleciona conteúdos e institui seu ponto de partida; e menos com base na "atenção" às questões que emergem. ${ }^{9}$

9 Conferir o artigo de Tim Ingold $O$ Dédalo e o Labirinto: caminhar, imaginar e educar a atenção (INGOLD, 2015) para uma discussão acerca da "intenção" e "atenção" nos
Significativamente, o "fator de situação", o "começar pelo meio", podem ser considerados a matéria própria da investigação etnográfica, acessados pela prática da observação participante, pelo movimento de acompanhar os processos da cultura em se fazendo; perseguindo a diferença em seu caráter emergente. Desse modo, no âmbito do fazer etnográfico, a ideia de "começar pelo meio" liga-se à possibilidade de sustentar o não-saber, que ocorreu tanto por parte dos alunos quanto da professora. Em nosso caso, isso aconteceu na medida em que foi feita uma aposta de não delimitação de um programa pronto, ou seja, sem definição $a$ priori de temas ou autores a serem aprendidos. Houve apenas a proposição de alguns conceitos iniciais e, especialmente, a construção de um determinado modo de trabalhar que aos poucos foi permitindo delinear questões. Nesse sentido, elementos do fazer etnográfico inspiraram o próprio planejamento pedagógico, na medida em que houve um esforço de levar a sério e trabalhar com as inquietações dos próprios estudantes - abrindo oportunidade para se estudar a cultura "em ato", viva.

\section{0 "problema" como dispositivo de educação da atenção}

Do ponto de vista do planejamento pedagógico e das pesquisas dos estudantes, as questões elaboradas pelos grupos podem ser concebidas como "analisadores", ${ }^{10}$ dada sua capacidade simultânea de colocarem a realidade em análise e de se constituírem enquanto "operadores de intervenção" (ROSSI; PASSOS, 2014, p. 19). Da mesma forma em que foi narrada a situação em que emergiu o "cabelo" como ponto de atenção, seria possível explorar o processo de formulação de cada um dos problemas de pesquisa. Estes poderiam ser acionados como ferramentas para investigar as tensões que perpassam o cotidiano desses joprocessos educativos.

10 "Analisador" é um conceito-ferramenta criado por Félix Guattari, exposto no livro Psicanálise e transversalidade, conforme Rossi e Passos (2014). 
vens. Nesse sentido, junto da atitude de levar a sério as inquietações que os alunos manifestam - similar à postura do antropólogo com seus sujeitos de pesquisa - foi importante conferir tempo e recursos para que essas inquietações fossem lapidadas com os estudantes, já que não se apresentavam espontaneamente. Sendo assim, a pesquisa teria continuidade ao saírem da generalidade temática em direção à proposição problemática singular: "o que, neste tema, vocês querem saber mais e com qual justificativa?"

Foi necessário, portanto, um tempo para a confecção do problema, o qual passou a operar como dispositivo de educação da atenção, na medida em que indicou um foco de preocupação ao precipitar uma linha, um caminho de investigação a ser perseguido tanto pelos alunos quanto pela professora. Nesse exercício, o grupo mencionado anteriormente deu continuidade à ideia de explorar a problemática evocada pelo "cabelo", transformando-a em uma questão específica: "Qual a influência da estética na construção da identidade dos jovens?" Após a elaboração das questões iniciais, fomos traçando percursos metodológicos para cada grupo, os quais envolviam necessariamente a observação participante com escrita de diário de campo e entrevistas qualitativas para as quais discutíamos os roteiros -, além da complementação com questionários fechados em alguns casos. Podemos observar a seguir alguns exemplos de problemas de pesquisa elaborados pelos grupos das cinco turmas, os quais esboçam um mapa de suas afecções:

1. Qual a influência da estética na construção da identidade dos jovens?

2. Existem hierarquias na arte da fotografia?

3. Quais os preconceitos sofridos pelos homossexuais atualmente?

4. Hoje em dia, qual a credibilidade que a mídia passa quando influencia na opinião política dos estudantes do Ensino Médio?

5. Quais as dificuldades das pessoas com deficiência em seus cotidianos?

6. Como as pessoas enxergam a cultura do estupro?
7. Como as escolas do bairro proporcionam espaço para a liberdade de expressão dos alunos?

8. Por que os usuários recorrem ao uso de drogas?

9. Por que há tantos movimentos separatistas no Rio Grande do Sul? Como eles se organizam?

10. Como espíritas e evangélicos veem a homossexualidade?

11. Como pessoas de diferentes origens percebem a cultura aqui no Sul?

12. Como a política funciona no Campus? Os alunos e servidores sentem que há espaço para divergências políticas?

13. Como o preconceito afeta os gamers e os games?

14. Como os jogos influenciam na educação?

15. Que significado os compradores de artesanato indígena atribuem a esses artefatos?

16. Qual é a influência da música no comportamento dos adolescentes e na formação de sua identidade?

17. Por que são criados estereótipos a partir de estilos musicais?

18. Quais as disputas em torno das definições do rap?

19. Como membros de diferentes religiões expressam sua fé?

20. Por que existem tantos conflitos entre as diferentes religiões? ${ }^{11}$

Como podemos ver, a dedicação à confecção de problemas alinhados às suas inquietações complexifica possíveis delimitações temáticas prévias. Por exemplo, se atentarmos para as questões 16, 17 e 18, podemos identificar um possível tema comum. Nos momentos iniciais de conversa em aula, ocorreu para os três grupos um interesse imediato pela música. Contudo, mesmo com um aparente começo comum, os problemas elaborados possibilitaram distintos caminhos, evidenciando diferentes situações vivenciadas por eles, as quais puderam ser trazidas à tona para análise. Os dois primeiros grupos, da mesma turma de 2016, eram formados majoritariamente por estudantes que tocavam instrumentos musicais e formavam bandas de rock com colegas da escola ou de fora

11 Nota do Diário de Campo da pesquisa registrada em abril de 2016. 
dela. O primeiro grupo, com a questão "Qual é a influência da música no comportamento dos adolescentes e na formação de sua identidade?", manifestou a vontade de entender os sentidos e o papel da música na vida de jovens que tocam instrumentos, cantam ou participam de projetos musicais. Alguns deles traziam dúvidas sobre as possibilidades de seguir trabalhando profissionalmente como músicos. ${ }^{12}$

Já o segundo grupo, da mesma turma, partia de um incômodo com relação à hierarquização dos estilos musicais. Diante das discussões sobre relativismo e etnocentrismo, questionavam-se se haveria critérios objetivos para definir se um estilo musical era superior a outro, já que relataram haver conflitos entre seus amigos com relação a isso. Incomodavam-se com colegas que desprezavam ofunk e o pagode, afirmando a superioridade do rock e de outros estilos. 0 grupo, então, buscou referências sobre o tema, realizou entrevistas qualitativas com colegas e professores da escola e recebeu indicações de leituras sobre a origem dos estilos musicais, especialmente atentando ao recorte étnico-racial e de classe envolvido no histórico dos movimentos artísticos e musicais. Em um dos dias marcados para compartilharem o andamento da pesquisa com a turma, trouxeram a argumentação sobre a estigmatização de alguns estilos musicais baseada em estereótipos:

Os entrevistados concordam que existem, em nossa sociedade, variados estereótipos musicais, e se dão por conta da ação da mídia, que impõe pensamentos como 'Pagode é coisa de maloqueiro' ou 'Funk é coisa de favelado'. Assim, ela acaba generalizando, dizendo que todos são assim, negando outros fatores presentes. ${ }^{13}$

Durante a apresentação, uma discussão acalorada se iniciou, já que um integrante do

12 Ao longo da pesquisa, compartilharam com a turma projetos sociais que envolviam música e, como produto final, apresentaram uma conta do Instagram onde postaram fotos e textos que produziram ao longo do ano e que mostravam diferentes sujeitos e situações em que a música se fazia presente, desde músicos tocando na rua, colegas na escola, músicos se apresentando em bares etc.

13 Trecho do Relatório Parcial da Pesquisa produzido pelos estudantes, registrado em junho de 2016. primeiro grupo não concordava que se poderia equivaler os estilos musicais. Para ele funk era "ruim e pronto". Evidenciou-se então o foco do conflito mencionado pelos integrantes do grupo, quando justificaram a escolha da questão de pesquisa:

Após um tempo de debate, em que o estudante do primeiro grupo estava irredutível, ele menciona: 'além de tudo meus pais têm uma desavença com um vizinho que ouve funk muito alto'. Ele explica a situação [...]. Imediatamente a turma acusa-o de estar sendo etnocêntrico, generalizando sobre uma cultura a partir de sua visão pessoal. 0 estudante parecia encarnar justamente o foco da crítica que o grupo tinha recém apresentado - ou seja, a estigmatização operada pela generalização. A aula foi se estendendo além do período de cinquenta minutos. 0 professor do horário seguinte já estava esperando à porta. Diante do clima de hostilidade, tentei intervir dizendo que quando o estudante nos contava sobre sua situação particular com relação ao vizinho, isso fazia com que pudéssemos também nos colocar no lugar dele, lançar um olhar de relativização e compreender por que ele vem sendo tão hostil ao funk - estilo musical ouvido por muitos ali. Restava, agora, ele próprio fazer esse exercício de relativização também, já que tinha responsabilidade sobre o que dizia, dado que o grupo havia apresentado que quando se julga um estilo musical, se julga também os grupos que estão em sua base e origem..$^{14}$

A tensão que apareceu nessa aula não foi completamente resolvida pelo debate ou pela minha fala em tom pedagógico, conciliatório. A questão retornou a partir de outras conversas extraclasse e em novos momentos de compartilhamento das pesquisas. Surgiram discussões sobre o acesso diferenciado aos estilos musicais e a percepção de que a influência da família e do bairro onde se vive é forte na criação de um "gosto". A ideia de que é preciso quebrar os estereótipos, mas também que "deveriam ter acesso a tudo" foi discutida em algumas ocasiões e apareceu nas entrevistas feitas pelo segundo grupo.

14 Nota do Diário de Campo da pesquisa registrada em junho de 2016. 
Um pouco diferente da discussão propiciada por estes dois grupos em 2016, no ano seguinte, o terceiro grupo interessado em música fez surgir outras situações para análise por meio da questão: "Quais as disputas em torno das definições do rap?". O grupo era composto por três meninos que ouviam muito esse estilo musical e começavam a compor e a participar de batalhas de rap na cidade. Primeiramente se interessavam por entender por que existiam diferentes estilos do rap, os quais geravam divisões e preconceitos no movimento. Problematizaram a influência da indústria cultural no fato de rappers famosos produzirem músicas de cunho "mais comercial e menos engajado". Quando apresentaram em aula as primeiras reflexões da pesquisa, surgiu um debate em torno do que seria um "rap engajado socialmente". Colegas da turma questionaram o fato de músicas que falam de temas como "amor e relacionamentos" não serem consideradas "engajadas". Isso deu origem a um longo debate: "falar de amor não seria também falar da vida na comunidade e tudo que perpassa ela? Não seria também ser engajado socialmente?" Além desse debate provocado pela pesquisa do grupo, ao longo do trabalho de campo, ao observarem eventos de rap e fazerem entrevistas com frequentadores, o grupo acabou atentando a outra questão: a pouca participação de mulheres e algumas iniciativas para estimular que tivessem mais visibilidade no movimento hip hop. Levaram essa questão à aula em outro momento.

Os exemplos trazidos aqui são um pequeno recorte da potência de acompanhar os estudantes a partir de problemáticas forjadas por eles. Episódios assim ocorreram em diferentes aulas nas quais os jovens trouxeram resultados parciais e finais das pesquisas. Conflitos latentes e preconceitos velados vinham à tona e eram analisados. Observa-se que trazer as questões ao debate coletivo na turma não tinha por objetivo conciliar diferenças ou dirimir tensões, mas abordar essas questões de outros modos, renomeando e colocando-as em evidência. Do ponto de vista da docência, essa prática possibilitou localizar os estudantes como ativos produtores de cultura - isto é, de diferença -, bem como de reflexões potentes sobre ela. Nesse sentido, o lugar docente ligou-se menos à seleção de temas e conteúdos e mais a um acompanhar percursos, desenvolvendo uma disposição por aprender sobre as questões que os alunos traziam e que a princípio não constariam nos planos de aula daquele modo. Exigia, portanto, a busca por outros repertórios teóricos, materiais e referências, em um processo dinâmico que se renovava a cada semana a partir da troca com os estudantes. Nesse sentido, menos do que "levar" a diversidade enquanto tema a ser debatido, a perspectiva etnográfica, tal como experimentada, possibilitou "atentar" e trabalhar com a potência que já estava ali. Os problemas de pesquisa tornavam-se dispositivos de educação da atenção tanto discente quanto docente, na medida em que permitiam uma "afinação da percepção ao" entorno (INGOLD, 2010).

\section{Experimentar e compartilhar o não-saber: etnografia e intervenção pedagógica}

No processo de educar a atenção à cultura como acontecimento, percebemos que as ocasiões de compartilhamento dos percursos das pesquisas com a turma tornaram-se importantes espaços de troca e aprendizado. Esses momentos foram organizados ao longo do ano, de modo que cada grupo deveria preparar algo para apresentar à turma, mediando um debate. Um aspecto que chamou atenção nesse processo foi o modo como esses momentos se tornaram, pela atuação dos grupos, não apenas espaços de intervenção pedagógica, mas também eram tomados por eles como "campo" de pesquisa. Para boa parte dos alunos, o momento de compartilhar seus resultados de pesquisa envolvia provocar reflexões coletivas que eram incorporadas à própria investigação - seja pela 
troca de experiências realizada ou pela aplicação de algum questionário ao final do debate. Da mesma forma, esses momentos tornavam-se chave para que eu fizesse intervenções com o coletivo e pudesse identificar a necessidade de mediações ou indicação de referências. Criava-se, tanto para os alunos quanto para mim, uma indissociável relação entre pesquisa de caráter etnográfico e intervenção pedagógica - podendo ser esta a associação que evidencia a particularidade dos usos da etnografia como ferramenta na escola.

Nesse sentido, a vivência com os estudantes ia modulando uma forma de fazer pesquisa que envolvia uma busca coletiva por respostas, as quais não residiam apenas na interpretação das narrativas dos estudantes - solução clássica da etnografia como "escrita sobre a cultura"; nem nas teorias sociais e exemplos que eu pudesse apresentar enquanto professora - solução tradicional da educação escolar. Tratava-se de trilhar um caminho juntos, compartilhando incertezas e um não-saber, na composição de um "plano comum"15 de aprendizagem. Enquanto construção de um determinado modo de fazer Antropologia, podemos aproximar esse movimento daquilo que Ingold (2016a) defende como caráter "experimental" ou "especulativo" da Antropologia, relacionado a estudar "com" as pessoas e não "sobre" elas. Isto é, juntando-se aos sujeitos em busca de respostas fundamentais da vida - imaginando mundos possíveis - e não apenas coletando dados para posterior análise (INGOLD, 2016a).

Sobre esse compartilhamento de incertezas e percursos que envolvia pesquisa e intervenção, um exemplo interessante ocorreu com o grupo que em 2016 formulou a pergunta: "Existem hierarquias na arte da fotografia?" Seus questionamentos se davam a respeito da pluralidade das definições em torno da arte e suas exclusões. Perguntavam-se: "Por que uma fotografia tirada por alguém pode estar

15 Inspiro-me aqui na proposta da cartografia enquanto pesquisa participativa, inspirada nas ideias de Gilles Deleuze e Felix Guattari (KASTRUP; PASSOS, 2013). num museu e uma selfie tirada por mim não é considerada arte? Quem define o que é arte?" Os três integrantes do grupo eram interessados em teatro, dança e fotografia; participavam de atividades artísticas na escola e fora dela. Questionavam-se também sobre as razões da arte feita na periferia não estar nos museus, sendo que eles conheciam vários artistas no bairro. Além de vídeos e outros materiais, indiquei a eles um texto sobre as ideias de Pierre Bourdieu acerca do campo artístico. Como compartilhamento parcial da investigação, o grupo propôs uma espécie de oficina com a turma. Entregou a cada colega uma placa de papel onde se lia de um lado "Arte" e do outro "Não arte". Iniciaram com um questionamento à turma sobre "o que é arte" e foram listando os critérios ouvidos no quadro. Depois disso, apresentaram fotografias e para cada uma delas os colegas deveriam julgar se eram arte ou não, levantando as placas, conforme os critérios criados coletivamente. Um rico debate se instaurava a cada divergência de opiniões. Essa oficina serviu, então, de base para que o grupo elaborasse os roteiros de entrevista que foram feitas com um artista, um colega e um professor da escola.

Entretanto, em meio aos debates, observações, entrevistas e trocas de materiais, o grupo se mantinha angustiado com o fato de a pesquisa não chegar a uma definição mais acabada de arte. Deparavam-se com obras de artistas que tinham como propósito justamente desconstruir definições. Sentiam que quanto mais pesquisavam, mais complexa a questão ficava. Certo dia chegaram com a constatação de que "a pesquisa não teria um fim", como idealizaram, no sentido de uma resposta à questão de pesquisa. Davam-se conta de que a pergunta apenas havia ajudado a orientar o percurso. Ao final do ano, a crise da uma pesquisa que não tinha fim foi materializada por eles na criação de uma performance apresentada à turma, na qual eles mesclavam frases e percepções ouvidas com provocações a respeito da necessidade de definições. 
Outro exemplo de encontro entre pesquisa, intervenção e não-saber ocorreu em um dos compartilhamentos parciais do grupo que tinha como questão "Quais os preconceitos sofridos pelos homossexuais atualmente?". 0 grupo, composto por três meninas, escolheu apresentar à turma um vídeo chamado Love is all we need? (LOVE..., 2012), ${ }^{16}$ o qual mexeu com vários alunos que assistiram, com alguns chegando às lágrimas. No debate que se seguiu a ele, surgiu uma discussão interessante a respeito do caráter natural ou construído da homossexualidade. Diante do impasse, matérias sobre o assunto foram buscadas na internet até que os colegas homossexuais da turma foram convidados a contarem o que achavam, a partir de suas experiências pessoais. Não chegamos a uma resposta final. No entanto, abriu-se um espaço respeitoso no qual os estudantes se sentiram à vontade para relatar, e pensar juntos, sobre como foi o processo de se perceberem homossexuais e assumirem isso para a família e amigos. Além desta aula, a potência do vídeo trazido pelo grupo também fez com ele fosse comentado por estudantes de outras turmas da escola, deixando os alunos curiosos. Isso me fez ter de apresentá-lo em outras turmas interessadas, associando aos debates que estávamos fazendo nelas. Ou seja, a intervenção do grupo não se restringiu à sua turma, mas acabou reverberando pela escola. Como produto final, as alunas elaboraram um documentário com depoimentos de colegas, professores e pessoas da comunidade, o qual foi apresentado e debatido em uma sessão aberta.

Como foi possível perceber, se o percurso da pesquisa já foi permeado pela proposição de intervenções, ao final do ano os grupos ainda tinham como tarefa apresentar um produto que materializasse as aprendizagens experienciadas na pesquisa. Combinamos que esse produto deveria também ser um dispo-

16 0 vídeo, criado por Kim Rocco Shields, retrata uma sociedade reversa na qual relações homossexuais são tidas como dominantes e pessoas heterossexuais são discriminadas. sitivo de aprendizagem para outros colegas da escola. Com isso, além de documentários e performances, surgiram produções na forma de blogs, ensaios fotográficos, poemas, músicas, oficinas e instalações. Um exemplo de produto que se tornou dispositivo de aprendizagem foi a oficina chamada "Labirinto da desconstrução", a qual foi criada pelo grupo que perseguiu a questão "Quais as dificuldades das pessoas com deficiência em seus cotidianos?". A pesquisa de campo envolveu observações em uma escola de educação especial do bairro, além de entrevistas com professoras e alunos desta instituição e colegas da própria escola que tinham familiares com deficiência. A oficina consistia em um circuito o qual os colegas da turma deveriam percorrer, a cada etapa, com os olhos vendados, depois utilizando uma cadeira de rodas e, por fim, uma muleta - equipamentos que os estudantes conseguiram emprestados para a atividade. Segundo os estudantes, essa oficina teve por objetivo colocar-se no lugar das pessoas com deficiência, experimentando suas dificuldades e testando o quão acessível a escola era para esses sujeitos.

Por sua vez, o grupo que havia iniciado seus questionamentos sobre o "cabelo" concebeu a pesquisa e a intervenção final de uma maneira bastante cuidadosa, dando uma lição sobre "restituição" dos resultados da pesquisa. Após a formulação do problema - "Qual a influência da estética na construção da identidade dos jovens?" -, elaboraram roteiros de entrevistas qualitativas a serem realizadas com colegas de diferentes cursos e etapas, enfocando o modo como percebiam o impacto social de sua aparência, como eram suas escolhas estéticas etc. Ao final do ano, propuseram como produto uma instalação, na qual expuseram retratos dos colegas que foram entrevistados. Junto das fotografias havia espaços para o público escrever palavras que vinham à mente quando olhavam os retratos. Durante o tempo de exibição, os integrantes do grupo permaneceram ao lado das fotografias dialogando com o público, 
mediando a exposição. Por fim, eles se propuseram a retornar os retratos com os escritos aos participantes com o objetivo de propiciar uma nova conversa e reflexão sobre estética e identidade com os entrevistados da pesquisa.

0 caráter variado das trajetórias dos grupos e dos produtos finais nos ensina sobre a potência das relações entre Antropologia e educação. Na experiência de trabalhar "com" e não "sobre" os jovens, ou seja, quando nos dispomos a aprender com eles, modos inventivos de se fazer pesquisa e educação aparecem. Assim, se o pensar da interface entre Antropologia e educação demanda problematizar a relação entre pesquisa etnográfica e intervenção pedagógica, os jovens da Restinga foram mestres em nos mostrar potencialidades dessa relação.

\section{Considerações finais}

Neste texto busquei discutir relações entre Antropologia e educação a partir de uma experiência singular que reflete sobre os usos de elementos da etnografia enquanto ferramentas de ensino e aprendizagem na escola. Dentre os caminhos inventivos que a prática etnográfica pode levar, situei-me a partir de perspectivas que buscam restituir à cultura a dimensão do acontecimento no sentido de se opor a abordagens essencialistas e à lógica escolar do "plano de princípio ou finalidade" (DELEUZE; GUATTARI, 1997, p. 222). A aposta foi em não simplesmente levar - como "intenção" - a "cultura" e a "diversidade" enquanto temas previamente definidos a serem ensinados, mas cultivar a "atenção" aos movimentos já presentes - começando pelo "meio".

A abordagem etnográfica à emergência das coisas opera como ferramenta para ajudar os estudantes a formularem seus próprios questionamentos e a se responsabilizarem por eles em seus processos de aprendizagem. Atentar à "imanência" faz "desacelerar" a construção do mundo (STENGERS, 2018), permitindo a hesitação, a dúvida e a composição com os ou- tros. À luz da experiência narrada, possibilita promover situações de aprendizagem em um mundo que ainda não está pronto e, portanto, no qual os sujeitos podem se sentir responsáveis por sua confecção.

Assim, foi possível perceber que a aposta na não delimitação prévia de temas foi levando a uma construção conjunta, na qual trajetos e problemáticas se entrelaçavam em um trabalho constante de afinações, trocas e experimentação. Desse modo, "deixar-se afetar" (FRAVET-SAADA, 2005) pelas questões dos estudantes, longe de pôr em risco um projeto de ensino-aprendizagem pré-definido, tornouse justamente sua matéria-prima. Escrever diários e anotações sobre as aulas, ao mesmo tempo em que ia se constituindo minha investigação, também ia subsidiando o próprio ato de planejar; em uma forma de planejamento que se pretendia atenta aos fluxos e às relações que se iam tecendo. É nesse instante que a pesquisa deixa de ser apenas coleta de dados ou descrição da realidade, mas permite a composição de um plano comum de aprendizagem - e também de investigação.

Por fim, a experiência aqui discutida indica que uma docência de inspiração etnográfica exigiu resgatar a dimensão propriamente educacional da Antropologia (INGOLD, 2016a, 2018), fazendo com que a professora sustentasse com os alunos um não-saber, recolocando-se como mais uma aprendiz em campo - como uma companheira de jornada na confecção de mundos possíveis. Por fim, observo que as reflexões desenvolvidas aqui não se pretendem restritas ao recorte disciplinar da Antropologia ou à instituição escolar, mas se estendem aos espaços de aprendizagem que se ocupam da "cultura" e da "alteridade" de forma ampla. $\mathrm{Ou}$ seja, explorar potencialidades do fazer etnográfico na educação diz respeito não apenas a antropólogos ou professores de Ciências Sociais, mas pode subsidiar diferentes atuações que busquem aprofundar as relações entre educação e diversidade. 


\section{REFERENNCIAS}

BABILÔNIA 2000. Direção: Eduardo Coutinho. Rio de Janeiro: VideoFilmes, 2001.

BRASIL. Parâmetros Curriculares Nacionais para o Ensino Médio. Parte IV - Ciências Humanas e suas Tecnologias. Brasília, DF: Ministério da Educação, 2000. Disponível em: http://portal.mec. gov.br/seb/arquivos/pdf/cienciah.pdf. Acesso em: 10 jul. 2019.

BRASIL. Orientações Curriculares Nacionais para o Ensino Médio. Brasília, DF: Ministério da Educação, 2006. Disponível em: http://portal. mec.gov.br/seb/arquivos/pdf/book_volume_03_ internet.pdf. Acesso em: 10 jul. 2019.

BRASIL. Presidência da República. Casa Civil. Lei no 11.645, de 10 de março de 2008. Inclui no currículo oficial da rede de ensino a obrigatoriedade da temática "História e Cultura Afro-Brasileira e Indígena". Brasília, DF, 2008. Disponível em: http:// www.planalto.gov.br/ccivil_03/_Ato 2007 2010/2008/Lei/L11645.htm. Acesso em: 09 nov. 2019.

DELEUZE, Gilles. Lógica do sentido. São Paulo: Perspectiva, 2003.

DELEUZE, Gilles; GUATTARI, Félix. Mil platôs capitalismo e esquizofrenia. vol. 5. São Paulo: Ed. 34, 1997.

EUGENIO, Fernanda; FIADEIRO, João. Jogo das perguntas: o modo operativo "AND" e o viver juntos sem ideias. Fractal: Revista de Psicologia, Rio de Janeiro, v. 25, n. 2, p. 221-246, ago. 2013. Disponível em: http://www.scielo.br/scielo.php?script=sci arttext\&pid=S1984-02922013000200002\&lng=e n\&nrm=iso. Acesso em: 10 jul. 2019.

FAVRET-SAADA, Jeanne. Ser afetado. Tradução de Paula Siqueira. Cadernos de Campo, São Paulo, n. 13, p. 155-161, 2005.

GOOD Hair. Direção: Jeff Stilson. Atlanta: HBO Films, 2009.

INGOLD, Tim. Da transmissão de representações à educação da atenção. Educação, Porto Alegre, v. 33, n. 1, p. 6-25, jan./abr. 2010.

INGOLD, Tim. Trazendo as coisas de volta à vida: emaranhados criativos num mundo de materiais. Horizontes Antropológicos, v. 18, n. 37, p. 25-44, 2012.

INGOLD, Tim. O Dédalo e o labirinto: caminhar, imaginar e educar a atenção. Horizontes Antro- pológicos, Porto Alegre, ano 21, n. 44, p. 21-36, jul./dez. 2015.

INGOLD, Tim. Chega de etnografia! A educação da atenção como propósito da antropologia. Educação, Porto Alegre, v. 39, n. 3, p. 404-411, set./dez. 2016 .

INGOLD, Tim. On human correspondence. Journal of the Royal Anthropological Institute. v. 23, n. 1, p. 9-27, 2016b.

INGOLD, Tim. Anthropology and/as education. Abingdon: Routledge, 2018.

JASANOFF, S. States of knowledge: the coproduction of science and social order. New York: Routledge, 2004.

KASTRUP, Virgínia; PASSOS, Eduardo. Cartografar é traçar um plano comum. Fractal, Rio de Janeiro, v. 25, n. 2, p. 263-280, ago. 2013. Disponível em: http://www.scielo.br/scielo.php?script=sci arttext\&pid=S1984-02922013000200004\&lng=e n\&nrm=iso. Acesso em: 13 jul. 2019.

LOVE Is All We Need? Direção: Kim Rocco Shields. Produção: Dana Garner. Burbank: Wingspan Pictures, 2011. Disponível em: https://www. youtube $. \mathrm{com} /$ watch?v=9I70zUDKvS8. Acesso em: 15 jul. 2019.

MALINOWSKI, Bronislaw. Argonautas do Pacífico Ocidental. São Paulo: Abril Cultural, 1984.

McDERMOTT, Ray; RALEY, Jason Duque. The ethnography of schooling writ large, 1955-2010. In: LEVINSON, A. U. Bradley; POLOCK, Mica (ed.). A companion to the anthropology of education. Malden: Wiley-Blackwell, 2011. p. 34-49.

OLIVEIRA, João Pacheco de. Pluralizando tradições etnográficas: sobre um certo mal-estar na Antropologia. Cadernos do LEME, Campina Grande, PB, v. 1, n. 1, p. 2-27, jan./jun. 2009.

ROSSI, André; PASSOS, Eduardo. Análise institucional: revisão conceitual e nuances da pesquisa-intervenção no Brasil. Revista EPOS, Rio de Janeiro, v. 5, n. 1, p. 156-181, jun. 2014. Disponível em: http://pepsic.bvsalud.org/scielo. php?script=sci_arttext\&pid=S2178-700X2014000 100009\&lng=pt\&nrm=iso. Acesso em: 26 jun. 2019.

STENGERS, Isabelle. Reativar o animismo. Tradução de Jamille Pinheiro Dias. Belo Horizonte: Chão da Feira, 2017. (Caderno de Leituras, no 62). Disponível em: http://chaodafeira.com/wpcontent/uploads/2017/05/caderno-62-reativarok.pdf. Acesso em: 24 jun. 2019. 
STENGERS, Isabelle. A proposição cosmopolítica. Revista do Instituto de Estudos Brasileiros, n. 69, p. 442-464, abr. 2018.

ZAMBONI, Vanessa. Construção social do espaço, identidades e territórios em processos de remoção: o caso do bairro Restinga - Porto Alegre/RS. 2009, 188 f. Dissertação (Mestrado em Planejamento Urbano e Regional) - Programa ade Pós-Graduação em Planejamento Urbano e Regional, Universidade Federal do Rio Grande do Sul (UFRGS), Porto Alegre, 2009.

Recebido em: 15/08/2019 Aprovado em: 12/10/2019

(cc) $\mathrm{EY}$ Este é um artigo publicado em acesso aberto sob uma licença Creative Commons. 